\title{
Revista Typographica (1864): um estudo sobre sua forma e conteúdo
}

\section{Revista Typographica (1864): a study concerning its form and content}

Niedja de Oliveira Barbosa, Isabella Ribeiro Aragão

tipografia, artes gráficas, tipógrafos oitocentistas

Esse artigo apresenta os resultados de um estudo sobre a forma e conteúdo da Revista Typographica (1864), um dos vários periódicos que surgiram no século 19 elaborado para e por tipógrafos, que enxergaram naquele momento a necessidade de clamar pela melhoria do ofício, compartilhar o conhecimento vindo de fora, entre outros. Dessa forma, o estudo visa contribuir com o entendimento das do estado dos primórdios das artes gráficas no Brasil sob a perspectiva dos próprios tipógrafos, tal como revelar suas reivindicações.

typography, graphic arts, 19th century typographers

This paper presents the results of a study concerning the form and content of Revista Typographia (1864), one of the several periodicals that appeared in the 19th century, published for and by printers, who saw at that moment the need to call for the improvement of the craft, to share the knowledge coming from outside, among others. Thus, the study aims to contribute to the understanding of the state of the beginnings of graphic arts in Brazil from the perspective of the typographers themselves, as well as revealing their claims.

\section{Introdução}

Embora a tipografia tenha produzido grande parte dos impressos editoriais do século 19; muito pouco conhecemos sobre as práticas e interesses dos tipógrafos da época. Tendo em vista essa carência de conhecimento, o presente artigo pretende contribuir com a área do Design da Informação ao apresentar um estudo que analisou a forma e conteúdo da Revista Typographica, publicada no Rio de Janeiro em $1864^{1}$. Assim, pretendemos revelar os assuntos de interesse desses profissionais e o estado da arte tipográfica no período.

A metodologia da pesquisa se baseou nas indicações de Luca (2008) que, mesmo comentando que não há um procedimento único para fazer pesquisa histórica em periódicos, indica algumas etapas básicas que se relacionam com: a localização e entendimento do periódico; averiguação da materialidade dos impressos; caracterização do conteúdo;

\footnotetext{
${ }^{1}$ Os resultados expostos aqui fazem parte da pesquisa de iniciação científica de Niedja Barbosa, aprovada no edital Pibic/UFPE/CNPq 2020-2021: As práticas tipográficas no Rio de Janeiro oitocentista: com a palavra, os tipógrafos.
} Curitiba | Brazil | 2021 
especificação das imagens; identificação dos responsáveis pela publicação, colaboradores e público; caracterização das fontes de receita; e, em especial, análise da coleção de acordo com a problemática da pesquisa.

O levantamento do periódico foi realizado no acervo online da Biblioteca Nacional (BN), sendo encontrados doze exemplares, totalizando um semestre de publicações. Como a problemática da pesquisa se relaciona com fundição, composição e os interesses da classe, estabelecemos alguns assuntos a serem destacados ao longo da leitura do conteúdo, entre eles, formação dos operários e fundamentos da composição tipográfica.

A análise gráfica, realizada com o auxílio da plataforma Notion, observou os detalhes referentes a dimensões das páginas, desenhos tipográficos do cabeçalho e do título do jornal, separação das colunas, destaque das seções, caracterização de serifa e quantidade diferentes de tipos nos títulos, subtítulos das matérias e texto principal de cada exemplar.

\section{Sobre a Revista Typographica}

A Revista Typographica: órgão das classes graphicas do Brasil teve seu lançamento no dia 1 de Fevereiro de 1864 , sendo publicada no dia 1 e 15 de cada mês ${ }^{2}$ com oito páginas, exceto o exemplar de número 12, de 30 de julho. A partir dessa data não encontramos mais nenhuma edição na BN, porém no dia 12 de março de 1888 uma revista com mesmo nome, cabeçalho e endereço de publicação começou a circular no Rio de Janeiro. Segundo Luca (2020), trata-se de duas publicações diferentes que aproveitaram o mesmo cabeçalho.

A revista era vendida por uma assinatura de $6 \$ 000$ réis por ano ou $3 \$ 000$ por semestre ${ }^{3}$. Por conta dessa possibilidade de pagamento anual e pelos comentários de intenção de continuidade de publicação após o encerramento do primeiro semestre, a revista deve ter ficado à espera da permanência dos "favores e auxílios recebidos" (Revista, 1864, n.12, p.90) e assinaturas para começar o segundo semestre. A falta de anúncios em todas as edições, provavelmente, deve ter contribuído para a sua descontinuidade.

Os proprietários eram Luiz José de Carvalho Chavy, M. B. de S. Machado, . L. F. Bernard ${ }^{4}$. Chavy era o primeiro secretário da Imperial Associação Typographica Fluminense, ocupando o cargo de presidente algumas vezes, e também autor da subseção Melhoramentos tipográficos. Sobre os demais proprietários não achamos nenhuma informação no periódico.

A revista media $33 \times 23,5 \mathrm{~cm}$, pelo que informação da $B N$, e era dividida em quatro seções Revista Typographica, Artes, Literatura e Variedades - que variavam a frequência nas edições. A primeira seção é introdutória, com uma subseção referente a Associação. Em geral, esta apresenta a ata das reuniões, com solicitações de regularização da profissão, auxílios aos companheiros enfermos, entre outros assuntos.

\footnotetext{
${ }^{2}$ Informação impressa na última página de algumas edições, por exemplo, Revista Typographica, ano I, n. 1, p. 8, $01 / 07 / 1864$

${ }^{3}$ Ibid.

${ }^{4}$ Revista Typographica, ano I, n. 1, p. 2, 01/07/1864
} 
A seção Artes, repetida em todos os exemplares, apresenta assuntos relacionados ao estado da arte tipográfica da época, que exploraremos a seguir. O livro História da Typographia, do francês Paulo Dupont, era traduzido nesta mesma seção. Nos tópicos relacionados com literatura e variedades, os editores comentavam sobre situações que ocorriam na Europa, textos motivadores e filosóficos sobre grandes nomes como Napoleão e Platão, além de poesias.

Apesar da temática relacionada com a área gráfica, o projeto da revista seguia o padrão dos periódicos da época (figuras 1 e 2), sem muito espaço para relacionar forma e conteúdo. Segundo Cardoso (2009, p. 74), "o típico jornal da primeira metade do século 19 tinha poucas páginas e era impresso em duas colunas, com variedade mínima de fontes tipográficas, uso limitado de fios, bordas e ornatos gráficos e, ainda menos frequente, de imagens". Comparando periódicos da classe profissional dos tipógrafos, exibidos em Cardoso (ibid.), confirmamos a grande semelhança com $O$ echo da imprensa (1856). A revista analisada se destaca dos demais títulos pelo cabeçalho figurativo visto que os demais periódicos utilizam apenas tipos para compor esta parte, e também explora margens generosas.

O clichê do cabeçalho continha uma imagem de Gutenberg no centro, a única das edições, e nome da revista em um listel. As seções eram separadas por fio, com títulos em tipo serifado (figura 3), com exceção da primeira seção, e subtítulos seguindo um padrão consistente com tipo negrito serifado em tamanho menor. O corpo do texto é composto de um mesmo tipo serifado, com exceção da subseção relacionada a Associação, que utilizava o itálico para pequenos destaques.

Seguindo um "padrão tipográfico excepcional para a época" (Cardoso, 2009, p.108), a diagramação da revista é organizada de forma unificada, não dando destaque ou priorizando seções ou informações. A hierarquia gráfica, portanto, é utilizada apenas para separar o corpo do texto, título e subtítulo. Os tipógrafos, provavelmente, estavam mais preocupados em criar um jornal para discutir os interesses da classe em um projeto tipograficamente bem-feito para os padrões da época do que explorar inovações. Entretanto, pela reutilização do clichê alguns anos mais tarde, é possível vislumbrar que seu projeto deve ter causado algum impacto entre os trabalhadores do ofício. 
Figura 1: Primeira página da Revista Typographica. Fonte: Biblioteca Nacional

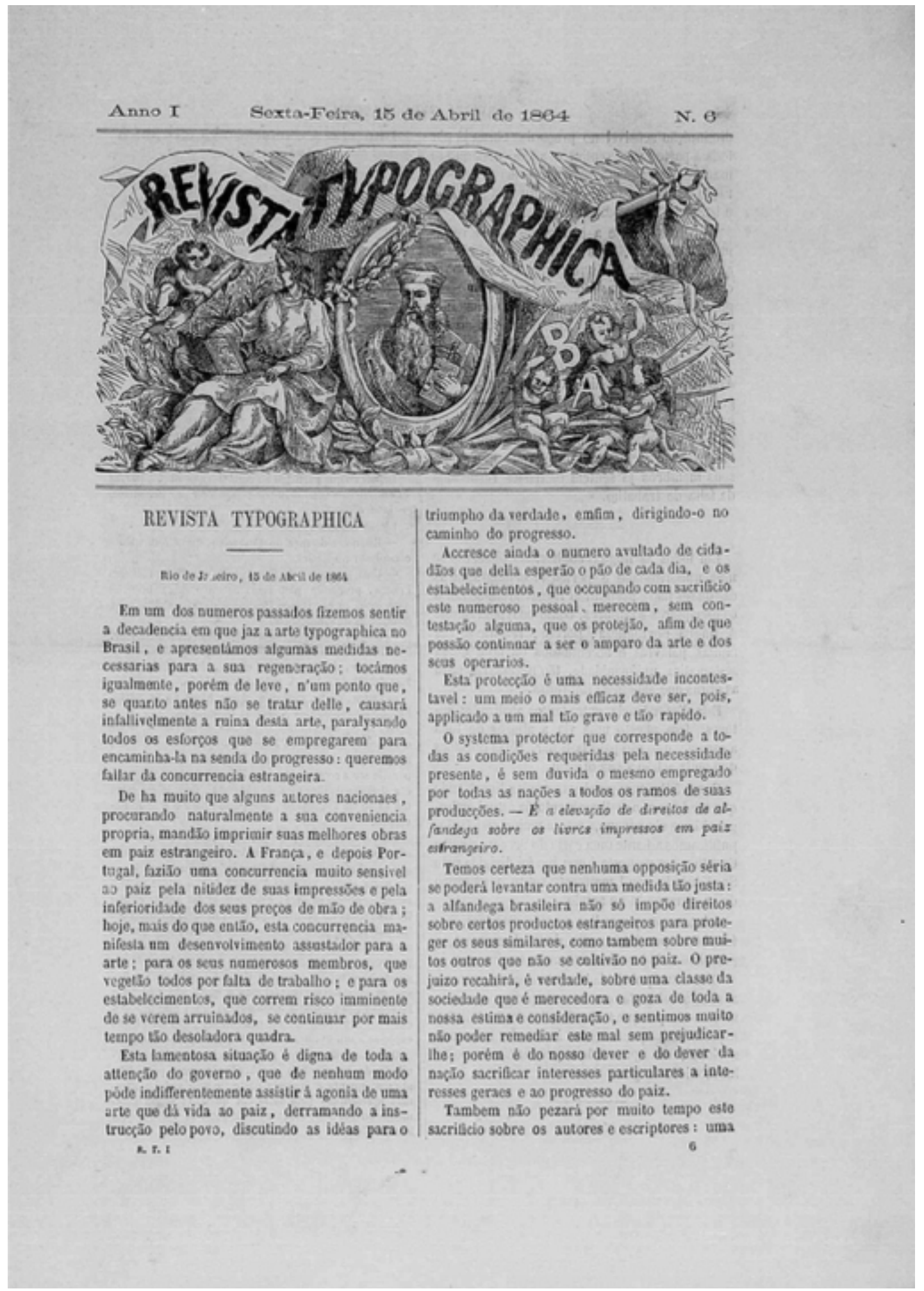


Figura 1: Segunda página da Revista Typographica. Fonte: Biblioteca Nacional

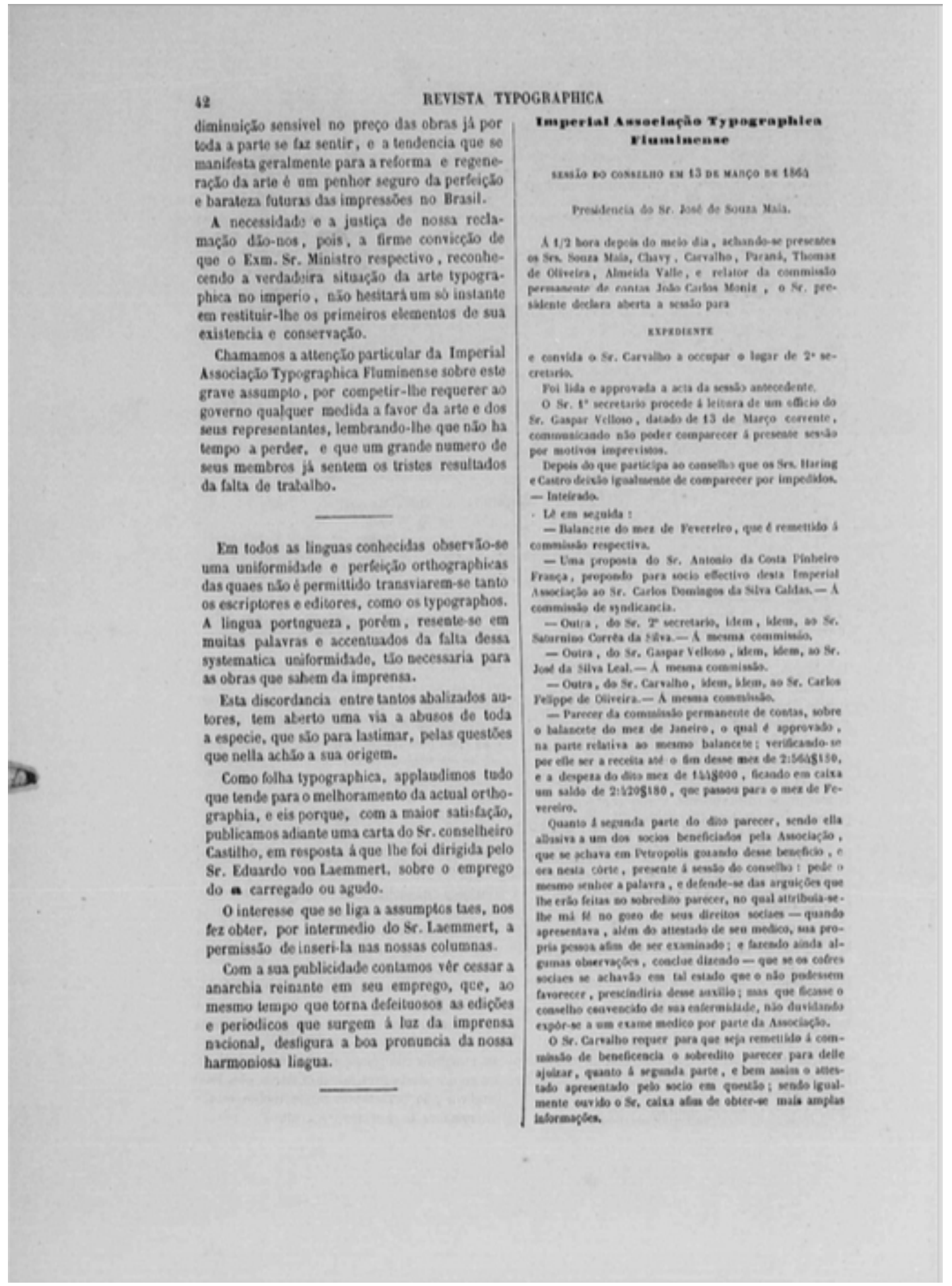

Figura 2: Tipos dos títulos e subtítulos das seções.

\section{ARTES}

A Imprensa 


\section{Com a palavra, os tipógrafos}

A introdução dos números 3 e 4 da revista clama por melhorias na formação dos profissionais e da arte tipográfica brasileira. Segundo os editores, as principais reclamações nas oficinas são "o desenvolvimento da fundição entre nós, que barateará o material, além das vantagens de ser feito no paiz; - e o ensino typographico, que formará bons e habeis artistas". (Revista, 1864, n.13, p.18)

Pela insatisfação das práticas feitas nas oficinas, a revista propõe um curso sobre a arte tipográfica, planejado pela Associação Typographica Fluminense:

Em conclusão, diremos que o curso proposto, theorico e pratico, deve abranger os seguintes ramos: $1^{0}$, Fundição de typos, por ser esta a ordem a seguir-se; $2^{\circ}$, Composição; $3^{\circ}$, Impressão; $4^{0}$, História geral da Typographia; $5^{\circ}$, Regulamentos, e condições hygienicas, em relação à fundação e regência de uma typographia. (Revista, 1864, n.4, p.26)

Por meio do conteúdo do curso proposto, é possível perceber que os tipógrafos estavam preocupados tanto com questões técnicas relacionadas às três atividades do ofício quanto conhecimentos gerais sobre a história da tipografia e o regulamento do comportamento nas oficinas. Para eles, o ensino praticado nos países europeus era determinante para a formação de habilidosos artistas gráficos "que apresentão trabalhos escoimados de erros e vicios, e economisão tempo e material" (ibid.). Em contrapartida, o cenário no Brasil gera "edições vergonhosas" (ibid.).

Na seção Revista Typographica do exemplar $10^{5}$, um artigo aborda o estabelecimento e estado da Tipografia comparando a situação brasileira e europeia. O texto comenta que, após a independência brasileira, os trabalhos tipográficos nacionais feitos em importantes tipografias, por exemplo, do Jornal do Commercio, do Diário do Rio, e Typographia Universal, não deixavam muito a desejar aos da Europa. Porém, enquanto lá fora a arte avançou em perfeição, aqui decaiu devido ao desamparo do governo.

Utsch e Martins (2020) se debruçaram sobre a Revista Typographica e O Typographo para comentar a insatisfação dos tipógrafos em relação à precariedade da produção de impressos brasileiros, ressaltando muitas vezes sua inferioridade perante as produções estrangeiras, principalmente aquelas impressas na França.

Em relação aos materiais tipográficos, a única questão abordada na revista foi o novo sistema de cunhos produzido pelos Srs. Marinoni \& Chaudré, engenheiros maquinistas de Paris. Segundo Arezio (2017), os cunhos são peças de madeira ou metal que servem para apertar os tipos na rama tipográfica. A inovação deu-se pelos cunhos mecânicos prontamente incorporado à Officina Typographia Universal dos Srs. Laemmert, local de impressão da revista:

\footnotetext{
${ }^{5}$ Revista Typographica, ano I, n. 10, p. 75, 15/07/1864
} 
O cunho de madeira acaba de ser substituído, de uma maneira commoda e admirável, por um utensílio mais duradouro e perfeito, que dispensa o emprego do martello e do bandulho, economisa tempo e melhora a execução do trabalho. (Revista, 1864, n.8, p.60)

A publicação tinha um grande interesse em levar ao leitor a história da arte tipográfica, engrandecendo a profissão e a invenção de Gutenberg. Apesar da revista não mencionar assuntos relacionados à composição tipográfica, um dos principais interesses da pesquisa, na introdução do último número ${ }^{6}$ os editores informam que a Imperial Associação Typographica Fluminense colocou à disposição alguns impressos e espécimes tipográficos alemães. Tanto essa nota quanto um pedido ${ }^{7}$ enviado pelo presidente da Associação para tipografias alemãs solicitando espécimes que possam servir de guia para os trabalhos artísticos brasileiros demonstram uma certa dependência de referências estrangeiras nas práticas dos tipógrafos cariocas oitocentistas.

\section{Considerações finais}

Diante do exposto nos doze exemplares da Revista Typographica, a quantidade de informações sobre as práticas compositivas em terras brasileiras é incipiente. As únicas menções se referem à criação do cunho mecânico que acabara de chegar na Typografia Universal e o método desordenado de trabalho das oficinas.

Com um projeto gráfico coerente com os demais jornais do período, utilizando-se de poucos tipos, mas com um diferencial do clichê do cabeçalho; os tipógrafos do periódico expuseram a precária situação das artes gráficas no Brasil, em comparação com a europeia, e clamaram pelo desenvolvimento da área de fundição de tipos e formação de um curso.

\section{Referências}

Arezio, A. (2017 [1936]). Dicionário de termos gráficos. São Paulo: Com-Arte.

Cardoso, R. (Org.). (2009). Impresso no Brasil, 1808-1930: destaques da história gráfica nos acervos da Biblioteca Nacional. Rio de Janeiro: Verso Brasil.

Luca, T. R. de. (2008). História dos, nos e por meio dos periódicos (1a ed. 2005; 2a ed. 2006, 2a ed. 1a reimpressão 2008). In: C. B. Pinsky (Org.), Fontes Históricas. 2ed.(2008, v. 1, p. 111-153) São Paulo: Contexto.

Luca, T. R. de. (2020). Revista Tipográfica (1888-1890): identidade profissional e condições técnicas nas oficinas tipográficas do Rio de Janeiro. Estudos Ibero-americanos, v. 46, p. 1-17.

Utsch, A.; Martins, B. (2020). Hacia atrás (y adelante). Apuntes para una historia del diseño gráfico en Brasil. In: M. G. Gravier, V. E. Devalle. (Org.). Diseño latinoamericano: diez

\footnotetext{
${ }^{6}$ Revista Typographica, ano I, n. 12, p. 90, 30/07/1864

${ }^{7}$ ibid., p.91.
} 
miradas a una historia en construcción, (v. 1, p. 247-283). Bogotá: Fundación Universidad de Bogotá Jorge Tadeo Lozano.

Revista Typographica. (1864). Rio de Janeiro, ano I, n.1-12.

\section{Sobre as autoras}

Niedja de Oliveira Barbosa, graduanda, UFPE, Brasil <niedja.obarbosa@ufpe.br> Isabella Ribeiro Aragão, Dra, UFPE, Brasil <isabella.aragao@ufpe.br> 